\title{
Phenomenology of depression in older compared with younger adults: meta-analysis
}

\author{
J. M. Hegeman, R. M. Kok, R. C. van der Mast and E. J. Giltay
}

\section{Background}

Late-life depression may differ from early-life depression in its phenomenology.

\section{Aims}

To investigate the effect of age on the phenomenology of major depression.

\section{Method}

A systematic search was conducted in PubMed, Embase and PsycINFO for all studies examining the relation between age and phenomenology of major depression according to RDC, DSM and ICD criteria. Studies were included only if the age groups were compared at the single-item level using the 17-, 21- or 24-item versions of the Hamilton Rating Scale for Depression; a meta-analysis was done for each item of the 17-item scale.

\section{Results}

Eleven papers met the inclusion criteria. Older depressed adults, compared with younger depressed adults, demonstrated more agitation, hypochondriasis and general as well as gastrointestinal somatic symptoms, but less guilt and loss of sexual interest.

\section{Conclusions}

The phenomenology of late-life depression differs only in part from that of early-life depression. Major depression in older people may have a more somatic presentation, whereas feelings of guilt and loss of sexual function may be more prevalent in younger people.

\section{Declaration of interest}

\section{None.}

Late-life depression is a common psychiatric disorder in old age. It often has a poor long-term prognosis, more frequently showing a chronic course and a higher relapse rate compared with depression at younger ages. ${ }^{1}$ In addition, late-life depression is linked to more medical comorbidity (e.g. cognitive impairment and cardiovascular diseases) and a high risk of mortality. ${ }^{2-4} \mathrm{~A}$ different phenomenology has been suggested for late-life compared with early-life depression. Possible reasons for a different presentation of late-life depression are the overlap of somatic symptoms of depression and physical disease in old age, and sociocultural factors such as the minimal expression of sadness in the current cohort of old people not used to complaining about depressed mood. ${ }^{5}$ Also, age-related biological and psychological factors may underlie a different phenomenology of late-life and early-life depression. In three narrative reviews insufficient evidence was found to support a different presentation of depression in older people. ${ }^{5-7}$ However, conceptual and methodological limitations of the reviewed studies, and the inherent subjectivity and bias proneness of narrative reviews, might have had a role in this conclusion. Therefore, this metaanalysis of studies examines the phenomenology of depression at the single-item level of the Hamilton Rating Scale for Depression (HRSD), also known as the Hamilton Depression Rating Scale (HDRS) or abbreviated to HAM-D.

\section{Method}

A systematic literature search was performed in PubMed, Embase and PsycINFO. The following (key)words were used: depress*, depressive, major depression, dysthymic disorder, geriatric patients, geriatric psychiatry, elder ${ }^{\star}$, elderly, geriatric, aged, old age, old, oldest old, middle aged, adult, adults, early onset, late onset, onset age, age of onset, age at onset, phenomenol ${ }^{\star}$, symptom $^{\star}$, clinical presentation, clinical features, atypical, melanchol $^{*}$ and dimension ${ }^{*}$. These were combined with the Medical Subject Headings (MeSH) depression, depressive disorder, signs and symptoms and age factors. The search was run on 18 July 2011. No limitation in the search strategy was inserted. Reference lists from all relevant literature were handsearched for additional relevant articles overlooked by the database search. Titles and abstracts of the articles were screened to identify possible relevant articles. Finally, the full texts of the remaining articles were reviewed (by J.H.) with respect to our inclusion and exclusion criteria. In cases of doubt, articles were discussed in a consensus meeting with three authors (J.H., R.K., R.M.).

Studies were excluded if no comparison was made between old age and younger age regarding the phenomenology of major depression; if studies did not present primary data (e.g. letters, comments and reviews were excluded); and if the study population consisted mainly of participants with bipolar disorder, schizoaffective disorder or dementia. Samples could be drawn from an in-patient, out-patient, primary healthcare or general population. As depression is a heterogeneous disorder irrespective of age, strict diagnostic criteria were used. Participants had to be diagnosed with major depression according to the RDC, ICD-9, ICD-10, DSM-III, DSM-III-R or DSM-IV criteria. The cut-off age for late-life depression had to be defined as being between 50 and 70 years; alternatively, correlation coefficients between age and item scores had to be presented. To increase homogeneity we included only studies in which symptoms of depression were measured using the HAM-D and both age groups were compared at the single-item level for the HAM-D-17, HAM-D-21 or HAM-D-24. Furthermore, the HAM-D is the most commonly used observer-rated and validated instrument for rating depression in both younger and older adults. ${ }^{8}$ Where articles reported data on overlapping cohorts, the studies with the largest sample size or with the most complete information were included.

Mean scores and standard deviations as well as frequencies of the 17 items of the HAM-D-17 for all HAM-D scales, mean total HAM-D scores (and standard deviations) and numbers of participants were extracted from the articles. From studies reporting frequencies of high- or low-severity scores on individual HAM-D items as well as presence of the item, the frequency of any 
presence at all was extracted. Correlations were extracted when articles provided only correlations between age and single-item scores. When only subsets of the 17 HAM-D items were presented, the authors of more recent studies (published after 1995) were contacted and requested to provide missing data. Where mean scores or correlations were presented separately for men and women or for early-onset and late-onset late-life depression, these were transformed into one weighted combined mean score (s.d.) or correlation coefficients using appropriate formulae.

\section{Quality assessment}

Quality assessment of observational studies in meta-analyses is not usual and there is no consensus regarding the method used. ${ }^{9,10}$ In our study the quality of the included studies was assessed by two authors (J.H., E.G.) using a checklist with the following five criteria:

(a) both age groups were selected from the same source population;

(b) population characteristics and inclusion and exclusion criteria were described;

(c) (semi)structured diagnostic instruments were used;

(d) difference in overall disease severity between younger and older patients controlled for, or no statistically significant difference in depression severity reported;

(e) a complete set of 17 HAM-D items was usable or transformable for meta-analysis.

For two criteria weighting was applied, resulting in quality criteria (a) through (c) being coded as 0 or 1 and criteria (d) and (e) as 0,1 or 2 points, and these criteria were summed to yield a score ranging from 0 to 8 points. If no information was provided as to whether a specific quality criterion was met, it was coded as 0 . The cut-off for high or low quality was defined at a score of 5 or more, based on the $60 \%$ cut-off point commonly used in quality assessments. ${ }^{11}$ Discrepancies between the reviewers were resolved through discussion (J.H., E.G.).

\section{Statistical analysis}

Data management, calculation of effect sizes and quantitative data synthesis were performed using the Comprehensive Meta-Analysis software version 2.0.021 for Windows (www.meta-analysis.com). Odds ratios were calculated for each HAM-D-17 item separately and then used for all mean comparisons. A higher odds ratio means that the particular HAM-D item showed higher prevalence rates and/or greater severity in older $v$. younger patients. Because considerable heterogeneity was expected, all analyses were performed with the random-effects model that reduces the risk of a type 1 error (as fixed models typically result in narrower confidence intervals). To assess heterogeneity between the studies we calculated the $I^{2}$, which is an indicator of heterogeneity in percentages, and used a value of $50 \%$ or over to indicate meaningful heterogeneity. ${ }^{12}$ In addition, $Q$ statistics were calculated. A statistically significant $Q$ rejects the null hypothesis of homogeneity and indicates a heterogeneous distribution of effect sizes between studies, meaning that systematic differences, possibly influencing the results, are present. For each HAM-D-17 item two summary estimates were calculated: an estimate based on all studies with usable data (see Fig. 2); and an estimate based on the studies with a quality score of $\geqslant 5$ points, to estimate the effect of bias and potential confounding. A $P$-value below 0.01 was considered statistically significant, because of multiple testing for every HAM-D item.

\section{Results}

The search yielded 3037 articles, including 2200 in PubMed, 773 in Embase, 53 in PsycINFO and 11 hand-searched articles. Exclusion of duplicates and irrelevant references after a first screening of the titles and abstracts left 129 potentially relevant articles for further evaluation (Fig. 1). Most articles were excluded because they did not report the outcome of interest (65 studies), most comparing the phenomenology of early-onset $v$. late-onset late-life depression (20 studies) or examining neurocognitive function rather than depressive symptoms in relation to age (14 studies). Of the 23 excluded articles not concerning a diagnosis of major depression, 21 reported on depressive symptoms, one reported on minor depression and one on dysthymic disorder. Finally, 11 articles were included in this meta-analysis comparing early and late-life major depression. Because some articles did not present all individual items of the HAM-D, three sets of authors were contacted. ${ }^{13-16}$ In one case we received data on the unreported HAM-D items. ${ }^{13}$ In the second case the authors were also asked whether two different articles presented data on the same study population. ${ }^{14,15}$ Although our question was not answered we extracted the data, choosing the article with the largest study population. As the HAM-D items 'weight loss' and 'anxiety' were not presented in this larger study, we extracted these data from the article with the smaller sample size. ${ }^{14,15}$ Data from a third article by this group were also included in this meta-analysis because the study population was without doubt a different group. ${ }^{17}$ In the third case, the author was unobtainable for further information concerning not reported or not transformable HAM-D scores and methodological issues. ${ }^{16}$ For this latter article, $Z$ scores and $P$-value statistics were used for the reported HAM-D items.

\section{Late-life $v$. early-life depression}

The characteristics of the included studies are shown in online Table DS1 and summarised in Table 1; the total number of

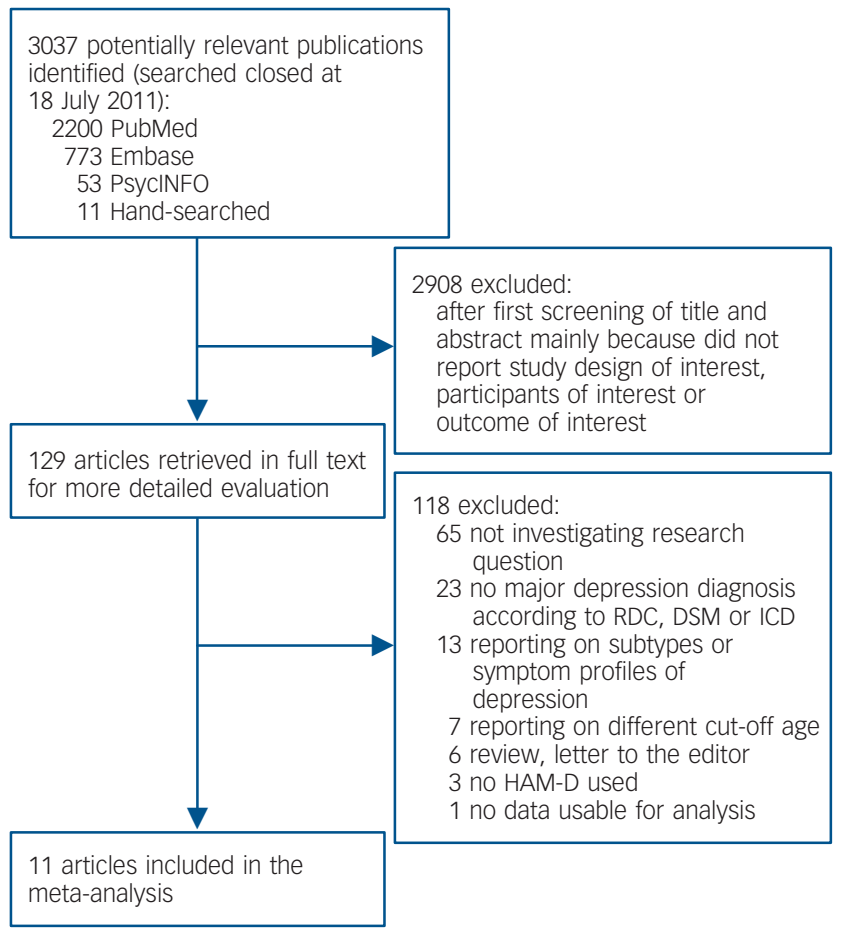

Fig. 1 Flow chart of study selection (HAM-D, Hamilton Rating Scale for Depression). 


\begin{tabular}{|c|c|c|c|c|c|c|c|c|c|c|c|c|c|}
\hline \multirow[b]{3}{*}{ Study } & & & & \multicolumn{6}{|c|}{ Age, years } & & & & \multirow[b]{3}{*}{$Q^{a}$} \\
\hline & \multicolumn{3}{|c|}{ Sample size, $n$} & \multicolumn{3}{|c|}{ Mean age } & \multirow[b]{2}{*}{ Cut-off age } & \multicolumn{2}{|c|}{ Mean age at onset } & \multicolumn{3}{|c|}{ HAM-D score: mean (s.d.) } & \\
\hline & EL & LL & All & EL & $\mathrm{LL}$ & All & & EL & LL & EL & LL & All & \\
\hline Brown et al (1984) ${ }^{18}$ & 28 & 63 & 91 & 39 & 64 & & 50 & 34 & 60 & $32.0(7.5)$ & $31.3(7.8)$ & & 7 \\
\hline Small et al $(1986)^{19}$ & 38 & 39 & 77 & 35 & 67 & & 55 & & & $22.1(5.0)$ & $22.7(6.1)$ & & 4 \\
\hline Brodaty et al (1991) ${ }^{17}$ & 181 & 61 & 242 & 37 & 69 & & 60 & & & $18.8(7.6)$ & $21.2(9.6)$ & & 5 \\
\hline Koenig et al (1993) ${ }^{21}$ & 26 & 44 & 70 & & & & $<40,70+^{b}$ & & & & & & 5 \\
\hline Wallace \& Pfohl (1995) ${ }^{23}$ & & & 257 & & & 39 & & & & & & & 5 \\
\hline Brodaty et al (1997) ${ }^{14}$ & 208 & 77 & 285 & 38 & 69 & & 60 & & & $20.8(6.5)$ & $25.2(7.1)$ & & 5 \\
\hline Stage et al (2001) $)^{22}$ & 228 & 233 & 461 & & & 55 & 55 & & & & & $23.1(4.4)$ & 6 \\
\hline Tan et al (2001) ${ }^{20}$ & 28 & 42 & 70 & 38 & 73 & & 60 & 35 & 69 & $23.8(5.2)$ & $26.5(6.3)$ & & 8 \\
\hline Brodaty et al (2005) ${ }^{15}$ & 242 & 40 & 282 & & & & 60 & & & $19.1(6.5)$ & $22.2(8.0)$ & & 5 \\
\hline Shahpesandy (2005) ${ }^{16}$ & 60 & 46 & 106 & 45 & 71 & & 65 & & & & & & 1 \\
\hline Gournellis et al (2011) ${ }^{13}$ & 30 & 69 & 99 & 45 & 70 & & 60 & 45 & 56 & $29.3(5.7)$ & $30.3(6.0)$ & & 8 \\
\hline All studies & & & 2011 & & & & & & & & & & \\
\hline \multicolumn{14}{|c|}{$\begin{array}{l}\text { EL, early-life depression; HAM-D, Hamilton Rating Scale for Depression; LL, late-life depression, NR, not reported. } \\
\text { a. Quality assessment score. } \\
\text { b. Participants were aged }<40 \text { or }>70 \text { years. }\end{array}$} \\
\hline
\end{tabular}

participants was 2011. On average, older patients had significantly more severe depression (seven studies with standardised difference in means 0.33 , 95\% CI $0.13-0.52 ; P=0.001) .{ }^{13-15,17-20}$ However, four studies did not report the overall HAM-D severity scores for older and younger patients. ${ }^{16,21-23}$ In fact, depression severity was particularly greater in older patients in the three studies by Brodaty et al. ${ }^{14,15,17}$ Apart from this, another study included a population with psychotic depression only, ${ }^{13}$ in which both age groups were severely affected. Small et al reported only on guilt. ${ }^{19}$ With regard to quality assessment we rated nine articles as being of high quality, ${ }^{13-15,17,18,20-23}$ and two articles as being of lower quality. ${ }^{16,19}$

$\begin{array}{llll} & \begin{array}{l}\text { Odds } \\ \text { ratio }\end{array} & \begin{array}{l}\text { Lower } \\ \text { limit }\end{array} & \begin{array}{l}\text { Upper } \\ \text { limit }\end{array} \\ \text { Hypochondriasis } & 3.132 & 2.240 & 4.378 \\ \text { Somatic - general } & 2.007 & 1.382 & 2.916 \\ \text { Agitation } & 1.842 & 1.388 & 2.445 \\ \text { Somatic - gastrointestinal } & 1.580 & 1.266 & 1.971 \\ \text { Weight loss } & 1.554 & 0.989 & 2.441 \\ \text { Insomnia - late } & 1.513 & 1.082 & 2.117 \\ \text { Anxiety - somatic } & 1.476 & 1.023 & 2.129 \\ \text { Loss of insight } & 1.305 & 0.858 & 1.984 \\ \text { Retardation } & 1.157 & 0.585 & 2.288 \\ \text { Work and activity } & 1.145 & 0.664 & 1.975 \\ \text { Insomnia - middle } & 1.141 & 0.833 & 1.564 \\ \text { Anxiety - psychic } & 1.127 & 0.779 & 1.630 \\ \text { Insomnia - early } & 1.125 & 0.887 & 1.427 \\ \text { Depressed mood } & 0.921 & 0.555 & 1.529 \\ \text { Guilt } & 0.524 & 0.424 & 0.646 \\ \text { Sexual interest } & 0.512 & 0.373 & 0.703 \\ \text { Suicidality } & 0.450 & 0.213 & 0.952\end{array}$

Z value

$\begin{array}{rr}6.679 & <0.001 \\ 3.657 & <0.001 \\ 4.229 & <0.001 \\ 4.052 & <0.001 \\ 1.914 & 0.056 \\ 2.417 & 0.016 \\ 2.079 & 0.038 \\ 1.243 & 0.214 \\ 0.418 & 0.676 \\ 0.487 & 0.626 \\ 0.824 & 0.410 \\ 0.636 & 0.525 \\ 0.972 & 0.331 \\ -0.318 & 0.750 \\ -6.020 & <0.001 \\ -4.138 & <0.001 \\ -2.088 & 0.037\end{array}$

Figure 2 presents the pooled odds ratios for the relation between age and symptoms of depression according to the HAM-D-17. Random effect modelling, with a 95\% confidence interval and $P<0.01$, showed that older people with major depression, compared with younger people, demonstrated more agitation $(\mathrm{OR}=1.84,95 \%$ CI $1.39-4.45, \quad P<0.001)$, general somatic symptoms $(\mathrm{OR}=2.01,95 \%$ CI $1.38-2.92, P<0.001)$, gastrointestinal somatic symptoms $(\mathrm{OR}=1.58,95 \%$ CI $1.27-1.97$, $P<0.001)$ and hypochondriasis $(\mathrm{OR}=3.13,95 \%$ CI 2.24-4.38, $P<0.001)$, but less guilt $(\mathrm{OR}=0.52,95 \%$ CI $0.42-0.65, P<0.001)$ and less loss of sexual interest $(\mathrm{OR}=0.51,95 \%$ CI $0.37-0.70$, $P<0.001)$ (Fig. 3). A sensitivity analysis of the nine articles of high

Sample size

Odds ratio and $95 \% \mathrm{Cl}$

$n \quad n$

$\begin{array}{lr} & \\ 9 & 1678 \\ 7 & 1154 \\ 6 & 1048 \\ 7 & 1154 \\ 7 & 1333 \\ 7 & 1154 \\ 8 & 1439 \\ 7 & 1154 \\ 7 & 1154 \\ 7 & 1154 \\ 7 & 1154 \\ 7 & 1333 \\ 6 & 1048 \\ 7 & 1154 \\ 9 & 1473 \\ 7 & 1154 \\ 6 & 1048\end{array}$

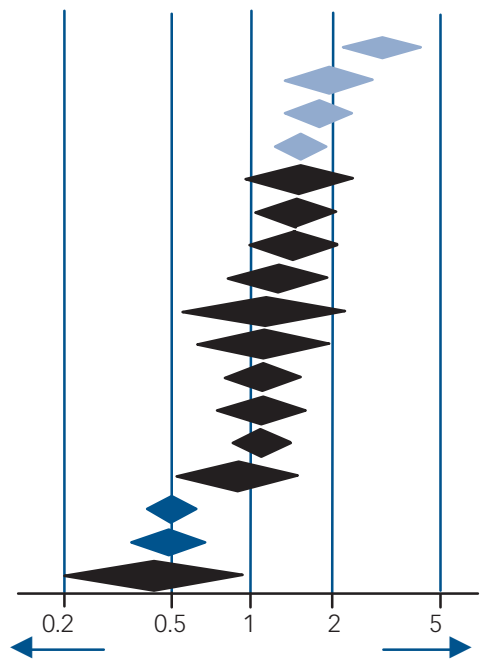

Early-life depression

Fig. 2 Forest plot of overall odds ratios (and their 95\% confidence intervals as the extremes of the diamonds) comparing early-life and late-life occurrence of every item of the 17-item Hamilton Rating Scale for Depression (HAM-D-17). Darker blue diamonds indicate the items are more prevalent and/or severe in younger patients, and the lighter blue diamonds that the items are more prevalent and/or severe in older patients. 


\begin{tabular}{|c|c|c|c|c|c|c|}
\hline \multirow[t]{2}{*}{ HAM-D-17 item } & & \multicolumn{4}{|c|}{ Statistics for each study } \\
\hline & & Odds & Lower & Upper & & \\
\hline \multicolumn{7}{|l|}{ Hypochondriasis } \\
\hline Brown et al (1984) & 91 & 2.250 & 0.995 & 5.089 & 1.948 & 0.051 \\
\hline Brodaty et al (1991) ${ }^{17}$ & 242 & 5.398 & 2.824 & 10.318 & 5.101 & $<0.001$ \\
\hline Koenig et al (1993) ${ }^{21}$ & 70 & 1.020 & 0.322 & 3.231 & 0.034 & 0.973 \\
\hline Wallace \& Pfohl $(1995)^{23}$ & 3257 & 2.688 & 1.693 & 4.269 & 4.192 & $<0.001$ \\
\hline Stage et al (2001) & 461 & 2.018 & 1.439 & 2.830 & 4.066 & $<0.001$ \\
\hline Tan et al (2001) $)^{20}$ & 72 & 7.497 & 2.960 & 18.989 & 4.249 & $<0.001$ \\
\hline Shahpesandy $(2005)^{16}$ & 124 & 3.336 & 1.594 & 6.978 & 3.198 & 0.001 \\
\hline Brodaty et al (2005) ${ }^{15}$ & 282 & 5.127 & 2.353 & 11.172 & 4.113 & $<0.001$ \\
\hline Gournellis et al (2011) $)^{13}$ & 99 & 3.447 & 1.555 & 7.643 & 3.046 & 0.002 \\
\hline Overall & 1698 & 3.132 & 2.240 & 4.378 & 6.679 & $<0.001$ \\
\hline \multicolumn{7}{|l|}{ Somatic - general } \\
\hline Brown et al (1984) ${ }^{18}$ & 91 & 1.000 & 0.446 & 2.242 & 0.000 & 1.000 \\
\hline Koenig et al (1993) ${ }^{21}$ & 70 & 1.508 & 0.411 & 5.538 & 0.619 & 0.536 \\
\hline Wallace \& Pfohl $(1995)^{23}$ & 257 & 1.516 & 0.968 & 2.376 & 1.817 & 0.069 \\
\hline Tan et al $(2001)^{20}$ & 72 & 6.824 & 2.709 & 17.188 & 4.074 & $<0.001$ \\
\hline Stage et al (2001) ${ }^{22}$ & 461 & 1.870 & 1.335 & 2.619 & 3.638 & $<0.001$ \\
\hline Shahpesandy $(2005)^{16}$ & 124 & 3.336 & 1.594 & 6.978 & 3.198 & 0.001 \\
\hline Gournellis et al (2011) & 99 & 1.734 & 0.794 & 3.788 & 1.381 & 0.167 \\
\hline Overall & 1174 & 2.007 & 1.382 & 2.916 & 3.657 & $<0.001$ \\
\hline \multicolumn{7}{|l|}{ Agitation } \\
\hline Brown et al (1984) ${ }^{18}$ & 91 & 2.562 & 1.130 & 5.812 & 2.252 & 0.024 \\
\hline Koenig et al (1993) ${ }^{21}$ & 70 & 1.128 & 0.425 & 2.990 & 0.242 & 0.809 \\
\hline Wallace \& Pfohl $(1995)^{23}$ & ${ }^{3} 257$ & 1.683 & 1.072 & 2.641 & 2.263 & 0.024 \\
\hline Stage et al $(2001)^{22}$ & 461 & 2.097 & 1.494 & 2.943 & 4.280 & $<0.001$ \\
\hline Tan et al $(2001)^{20}$ & 72 & 3.272 & 1.345 & 7.963 & 2.613 & 0.009 \\
\hline Gournellis et al (2011) & 99 & 0.978 & 0.449 & 2.128 & -0.057 & 0.955 \\
\hline Overall & 1050 & 1.842 & 1.388 & 2.445 & 4.229 & $<0.001$ \\
\hline \multicolumn{7}{|l|}{ Somatic - gastrointestinal } \\
\hline Brown et al $(1984)^{18}$ & 91 & 1.296 & 0.577 & 2.908 & 0.628 & 0.530 \\
\hline Koenig et al (1993) & 70 & 13.255 & 0.657 & 267.586 & 1.686 & 0.092 \\
\hline Wallace \& Pfohl $(1995)^{23}$ & 257 & 1.472 & 0.940 & 2.306 & 1.689 & 0.091 \\
\hline Stage et al (2001) & 461 & 1.494 & 1.070 & 2.087 & 2.354 & 0.019 \\
\hline Tan et al $(2001)^{20}$ & 72 & 1.103 & 0.463 & 2.626 & 0.222 & 0.825 \\
\hline Shahpesandy $(2005)^{16}$ & 124 & 2.457 & 1.194 & 5.057 & 2.441 & 0.015 \\
\hline Gournellis et al (2011) $)^{13}$ & 99 & 2.216 & 1.010 & 4.860 & 1.986 & 0.047 \\
\hline Overall & 1174 & 1.580 & 1.266 & 1.971 & 4.052 & $<0.001$ \\
\hline \multicolumn{7}{|l|}{ Guilt } \\
\hline Brown et al (1984) $)^{18}$ & 91 & 0.713 & 0.317 & 1.600 & -0.821 & 0.412 \\
\hline Small et al (1988) ${ }^{19}$ & 77 & 0.403 & 0.141 & 1.151 & -1.697 & 0.090 \\
\hline Brodaty & 242 & 0.967 & 0.521 & 1.795 & -0.107 & 0.915 \\
\hline Koenig et al (1993) & 70 & 0.545 & 0.154 & 1.933 & -0.939 & 0.348 \\
\hline Wallace \& Pfohl $(1995)^{23}$ & 3257 & 0.446 & 0.283 & 0.705 & -3.458 & 0.001 \\
\hline Stage et al $(2001)^{22}$ & 461 & 0.477 & 0.340 & 0.669 & -4.280 & $<0.001$ \\
\hline Tan et al $(2001)^{20}$ & 72 & 2.842 & 0.301 & 26.862 & 0.911 & 0.362 \\
\hline Shahpesandy $(2005)^{16}$ & 124 & 0.403 & 0.196 & 0.829 & -2.468 & 0.014 \\
\hline Gournellis et al (2011) ${ }^{13}$ & 99 & 0.482 & 0.220 & 1.055 & -1.826 & 0.068 \\
\hline Overall & 1493 & 0.524 & 0.424 & 0.646 & -6.020 & $<0.001$ \\
\hline \multicolumn{7}{|l|}{ Sexual interest } \\
\hline Brown et al (1984) ${ }^{18}$ & 91 & 0.322 & 0.141 & 0.734 & -2.696 & 0.007 \\
\hline Koenig et al (1993) & 70 & 0.211 & 0.073 & 0.609 & -2.875 & 0.004 \\
\hline Wallace \& Pfohl $(1995)^{23}$ & 3257 & 0.588 & 0.374 & 0.922 & -2.311 & 0.021 \\
\hline Stage et al $(2001)^{22}$ & 461 & 0.804 & 0.576 & 1.122 & -1.284 & 0.199 \\
\hline Tan et al $(2001)^{20}$ & 72 & 0.452 & 0.188 & 1.087 & -1.773 & 0.076 \\
\hline Shahpesandy $(2005)^{16}$ & 124 & 0.470 & 0.230 & 0.961 & -2.070 & 0.038 \\
\hline Gournellis et al $(2011)^{13}$ & 99 & 0.455 & 0.208 & 0.998 & -1.964 & 0.050 \\
\hline Dverall & 1174 & 0.512 & 0.373 & 0.703 & -4.138 & $<0.001$ \\
\hline
\end{tabular}

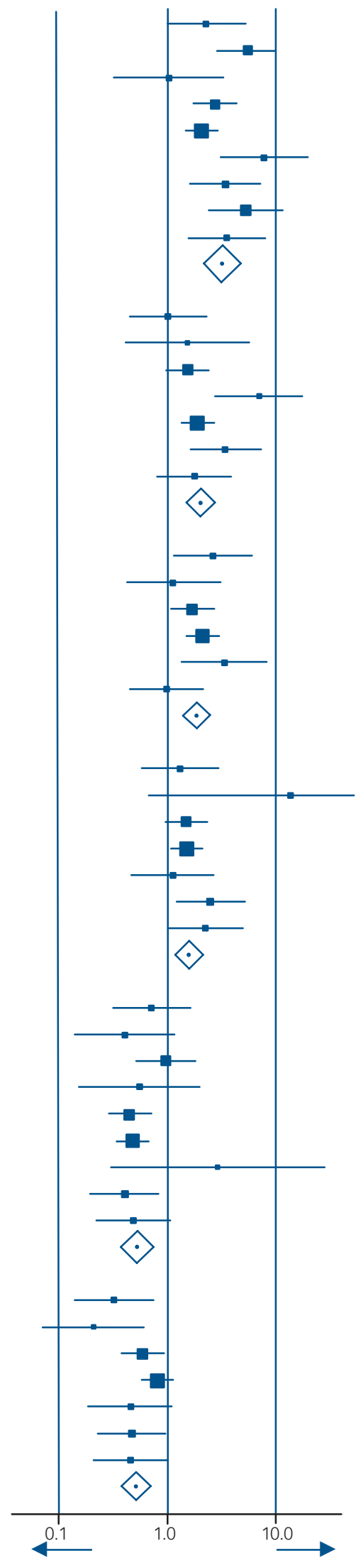

Early-life depression Late-life depression

Fig. 3 Forest plot for the six statistically significant items of the 17-item Hamilton Rating Scale for Depression (HAM-D-17) for the comparison between early-life and late-life depression $(P<0.01)$. 
quality revealed that the significant differences persisted for all six HAM-D-17 items. ${ }^{13-15,17,18,20-23}$ Another sensitivity analysis excluding studies with more severe depression in older people $v$. younger people revealed similar results. ${ }^{14,15,17}$ Again, removing the study with patients with psychotic depression only did not notably affect the sizes of the odds ratios, ${ }^{13}$ although these were no longer significant for loss of sexual interest and general and gastrointestinal somatic symptoms.

Heterogeneity between studies was not significant for the items agitation $(Q=6.44, P=0.26)$, gastrointestinal somatic symptoms $(Q=5.17, P=0.52)$, guilt $(Q=8.10, P=0.43)$ and loss of sexual interest $(Q=10.12 ; P=0.12)$, suggesting a homogeneous distribution of effect sizes between the studies. However, for the items hypochondriasis $(Q=17.90 ; P=0.02)$ and general somatic symptoms $(Q=13.17 ; P=0.04)$ the $I$ value was just above $50 \%$, which has a minor effect as we used random-effect models. No study was identified as a consistent outlier for most of the 17 HAM-D items.

\section{Discussion}

The results of this meta-analysis show a partly different phenomenology of late-life depression compared with early-life depression. Older people with major depression demonstrated more agitation, general and gastrointestinal somatic symptoms and hypochondriasis, but less guilt and less loss of sexual interest, compared with younger people with major depression. The difference between the two groups did not reach statistical significance for late insomnia, somatic anxiety and suicidality, which might be due to the small numbers of participants (type 2 error). In general, these results indicate that major depression in older people may have a more somatic presentation, whereas feelings of guilt and loss of sexual function may be symptoms that are more specific for depression at a younger age.

Our results are largely consistent with some earlier studies examining this subject in a different way from comparison at the HAM-D single-item level. For example, older people with major depression were found to be more likely to have somatic symptoms and less likely to have guilt, suicidal and cognitive symptoms. ${ }^{24}$ Another study found that older people were more likely to have agitation and late insomnia, ${ }^{25}$ whereas younger people were more likely to have increased appetite, weight gain and decreased libido. Similarly, in a study examining exclusively psychotic depression, ${ }^{26}$ an increase of agitation and a decrease of suicidality and guilt was found in old age compared with younger age. Husain et al used the 30-item Inventory of Depressive Symptomatology - Clinician Rated and found clinically meaningful differences. ${ }^{27}$ In their study older people with non-psychotic major depression had more gastrointestinal symptoms and middle and late insomnia, less irritability and hypersomnia, and were less likely to hold negative cognitions of the self or the future. Others, however, found no difference in the phenomenology of late-life and early-life depression. ${ }^{28-30}$ For instance, no difference in symptoms of major depression was found in an in-patient psychiatric population using the Duke Depression Evaluation Schedule for the Elderly. ${ }^{31}$ In addition, Corruble et $a l^{32}$ using the Montgomery-Åsberg Depression Rating Scale, found similar results in a comparison of the phenomenology of major depression at age $\geqslant 60$ years $v .<60$ years. In a sensitivity analysis we added the seven items that roughly corresponded to the HAM-D items, which did not lead to different conclusions (data not shown). In three reviews without quantitative data analysis it was argued that no clinically relevant difference was found. ${ }^{5-7}$ However, although the studies in these earlier narrative reviews almost overlapped with our studies, some recent articles were not included. Also, these differences in interpretation may relate to the advantages of a meta-analysis over a narrative review that is more prone to subjectivity and bias. Remarkably, in contrast to earlier studies, we did not find differences between older and younger age groups in the HAM-D items loss of insight, work and activity, and psychomotor retardation, which are closely related to the concept of apathy. ${ }^{33-35}$ Also, in spite of what has been suggested by others, ${ }^{5,36,37}$ no difference was found in depressed mood.

The question arises whether age-related factors modify the presentation of depression or just lead to overlap of somatic symptoms of depression and medical illness, both complicating the diagnosis of late-life depression. For example, not only decrease of sexual desire and sexual function with ageing, but also the lack of a living partner, might explain our finding that older patients had less sexual dysfunction caused by depression compared with younger patients. ${ }^{38}$ The expression of more somatic symptoms and less guilt in older patients might be explained by the tendency of the current cohort of older people to express somatic instead of psychological complaints. ${ }^{39}$ Alternatively, it might be that the phenomenology of late-life depression is related to specific risk factors; for instance, in the oldest old people, psychomotor retardation and loss of energy were associated with vascular or neurodegenerative risk factors, whereas symptoms such as thoughts of death, as well as sleep and appetite disturbances, were more strongly related to an inflammatory risk factor. ${ }^{40}$ However, another study on this subject reported conflicting results. ${ }^{41}$ Besides, it is difficult to distinguish apathy and cognitive impairment as distinct clinical entities from depression at old age because of overlap of symptoms. Again, it follows that depression may have been overestimated in these studies, suggesting a different phenomenology based on wrong assumptions. ${ }^{42,43}$

Several methods have been proposed to resolve the issue of overlap of somatic symptoms of depression and physical illness, complicating the diagnosis of late-life depression. For example, in an inclusive approach all somatic symptoms are included regardless of being primarily due to a medical illness, whereas in an exclusive approach somatic symptoms of depression are excluded and only psychological symptoms are counted for a diagnosis of depression. Next, in an aetiological approach a somatic symptom is only counted if not caused by a medical illness and in a substitutive approach the somatic symptoms are replaced by non-somatic alternatives. ${ }^{44}$ Although the HAM-D-17 has been criticised for use in patients with physical illness on the grounds that it includes too many somatic items, the use of this scale is even justified to diagnose post-stroke depression and depression in Parkinson's disease. ${ }^{45,46}$ Moreover, some somatic symptoms were highly sensitive for post-stroke depression. $^{45}$

\section{Strengths and limitations}

Our study has some limitations. First, older patients had on average a higher level of severity of depression than the younger patients, which may account for the slightly different phenomenology in older patients. Although statistically significant, these differences in depression severity were small and therefore not regarded as clinically relevant. In addition, sensitivity analysis excluding studies with significantly more severe depression in older people revealed similar results, ${ }^{14,15,17}$ suggesting that our results are unlikely to be explained by differences in depression severity. Alternatively, overlapping somatic symptoms of depression and comorbid age-related 
physical disorders may explain the higher scores on depression severity scales in the older population. Second, we could not adjust for comorbid physical disorders in older $v$. younger people. Lack of this information means that we cannot be certain whether our findings are related to somatic comorbidity. In fact, all but one study included in-patients, and perhaps older patients with a more somatic presentation were admitted to hospital more often than younger depressed patients in order to exclude an underlying somatic illness. In previous studies, however, differences in the phenomenology of major depression persisted after adjustment for somatic comorbidity. ${ }^{21,27}$ One of these studies was included in our meta-analysis and used an inclusive approach for rating HAM-D items. ${ }^{21}$ Third, as studies mainly reported on in-patients it follows that generalisation of our findings to an out-patient or general population is limited. Fourth, a conceptual limitation is the use of strict RDC, DSM and ICD diagnostic criteria for major depression and the HAM-D. Obviously, if distinctive features of late-life depression indeed exist, they would be missed if not included in the HAM-D. Moreover, if depression in older people presents with many symptoms that differ from the DSM or ICD criteria, then these patients might not be diagnosed as having depression and would not have been included in these studies. Finally, this meta-analysis focused on comparing depression at older and younger age, irrespective of age at first onset. It follows that we did not address the question of whether the age at onset of the first depressive episode is related to a specific symptom profile of early- or late-onset late-life depression. However, the studies of Gournellis et al and Brodaty et al compared both early $v$. late-life depression and early onset $v$. late onset in late-life depression. ${ }^{13-15}$ Gournellis et al found differences related to both age at onset and current age in which the group of older patients with early-onset depression had an in-between position concerning the extent of differences in hypochondrial ideation and gastrointestinal symptoms compared with a group of older patients with late-onset depression and a group of younger patients with early-onset depression. ${ }^{13}$ In the studies by Brodaty et al differences were found related to current age only, but not for age at onset. ${ }^{14,15}$ Furthermore, as late-life depression probably encompasses patients with recurrent depressive episodes and treatment-refractory depression, it is possible that differences in phenomenology between late-life and early-life depression might be more marked when studies include only patients with first depressive episodes. Ideally, these would be prospective cohort studies because recall bias of age at onset is one of the problems of such studies. ${ }^{47}$ However, older patients with recurrent depressive episodes might also have a 'new onset' distinctive depressive episode, for example related to (vascular) changes in the ageing brain.

Strengths of this meta-analysis include the thorough search resulting in over 2000 participants from 11 studies, the quality of the review process and the consistent findings across studies with generally low heterogeneity. Moreover, we are not aware of previous meta-analyses examining the relation between age and the phenomenology of major depression.

\section{Clinical implications}

In summary, the results of this study suggest only in part a different phenomenology of major depression in older people compared with younger adult patients. These findings are relevant for clinical practice, because we should be aware that major depression in older people may present in a more somatic way. This may help our understanding of the phenomenology of latelife depression related to certain risk factors and age at onset, in order to improve recognition and early detection, and refine prevention and treatment of depression in older people.

\section{J. M. Hegeman, MD, Department of Psychiatry, St Antoniusziekenhuis, Utrecht, and Department of Psychiatry, Leiden University Medical Centre, Leiden; R. M. Kok, MD, Department of Old Age Psychiatry, Parnassia, Den Haag; R. C. van der Mast, MD, E. J. Giltay, MD, Department of Psychiatry, Leiden University Medical Centre, Leiden,} The Netherlands

Correspondence: Dr Annette Hegeman, Department of Psychiatry, Leiden University Medical Centre, Albinusdreef 2, 2333 ZA Leiden, The Netherlands. Email: j.m.hegeman@lumc.nl

First received 21 Apr 2011, final revision 10 Nov 2011, accepted 30 Nov 2011

\section{References}

1 Mitchell AJ, Subramaniam $\mathrm{H}$. Prognosis of depression in old age compared to middle age: a systematic review of comparative studies. Am J Psychiatry 2005; 162: 1588-601.

2 Penninx BW, Beekman AT, Bandinelli S, Corsi AM, Bremmer M, Hoogendijk WJ, et al. Late-life depressive symptoms are associated with both hyperactivity and hypoactivity of the hypothalamo-pituitary-adrenal axis. Am J Geriatr Psychiatry 2007; 15: 522-9.

3 Penninx BW, Guralnik JM, Mendes de Leon CF, Pahor M, Visser M, Corti MC, et al. Cardiovascular events and mortality in newly and chronically depressed persons >70 years of age. Am J Cardiol 1998; 81: 988-94.

4 Baldwin RC, Gallagley A, Gourlay M, Jackson A, Burns A. Prognosis of late life depression: a three-year cohort study of outcome and potential predictors. Int J Geriatr Psychiatry 2006; 21: 57-63.

5 Baldwin RC. Depressive disorders. In Oxford Textbook of Old Age Psychiatry (eds R Jacoby, C Oppenheimer, T Dening, A Thomas): 529-56. Oxford University Press, 2008

6 Caine ED, Lyness JM, King DA, Connors L. Clinical and etiological heterogeneity of mood disorders in elderly patients. In Diagnosis and Treatment of Depression in Late Life: Results of the NIH Consensus Development Conference (ed LS Schneider): 23-39. American Psychiatric Press, 1994

7 Kok R. Atypical presentation of depression in the elderly: fact or fiction? [in Dutch]. Tijdschr Gerontol Geriatr 2004; 35: 65-71.

8 Bagby RM, Ryder AG, Schuller DR, Marshall MB. The Hamilton Depression Rating Scale: has the gold standard become a lead weight? Am J Psychiatry 2004; 161: 2163-77.

9 Mallen C, Peat G, Croft P. Quality assessment of observational studies is not commonplace in systematic reviews. J Clin Epidemiol 2006; 59: 765-9.

10 Sanderson S, Tatt ID, Higgins JP. Tools for assessing quality and susceptibility to bias in observational studies in epidemiology: a systematic review and annotated bibliography. Int J Epidemiol 2007; 36: 666-76.

11 Luppino FS, de Wit LM, Bouvy PF, Stijnen T, Cuijpers P, Penninx BW, et al. Overweight, obesity, and depression: a systematic review and meta-analysis of Iongitudinal studies. Arch Gen Psychiatry 2010; 67: 220-9.

12 Higgins JP, Thompson SG, Deeks JJ, Altman DG. Measuring inconsistency in meta-analyses. BMJ 2003; 327: 557-60

13 Gournellis R, Oulis P, Rizos E, Chourdaki E, Gouzaris A, Lykouras L. Clinica correlates of age of onset in psychotic depression. Arch Gerontol Geriatr 2011; 52: 95-8.

14 Brodaty H, Luscombe G, Parker G, Wilhelm K, Hickie I, Austin MP, et al. Increased rate of psychosis and psychomotor change in depression with age. Psychol Med 1997; 27: 1205-13.

15 Brodaty $\mathrm{H}$, Cullen $\mathrm{B}$, Thompson $\mathrm{C}$, Mitchell $\mathrm{P}$, Parker G, Wilhelm K, et al. Age and gender in the phenomenology of depression. Am J Geriatr Psychiatry 2005; 13: 589-96

16 Shahpesandy $\mathrm{H}$. Different manifestation of depressive disorder in the elderly. Neuro Endocrinol Lett 2005; 26: 691-5.

17 Brodaty H, Peters K, Boyce P, Hickie I, Parker G, Mitchell P, et al. Age and depression. J Affect Disord 1991; 23: 137-49.

18 Brown RP, Sweeney J, Loutsch E, Kocsis J, Frances A. Involutional melancholia revisited. Am J Psychiatry 1984; 141: 24-8.

19 Small GW, Komanduri R, Gitlin M, Jarvik LF. The influence of age on guilt expression in major depression. Int J Geriatr Psychiatry 1986; 1: 121-6.

20 Tan LL, Ng LL, Tan S, Roy K, Brodaty H, Parker G. Depression in Singapore: failure to demonstrate an age effect on clinical features. Int J Geriatr Psychiatry 2001; 16: 1054-60. 
21 Koenig HG, Cohen HJ, Blazer DG, Krishnan KR, Sibert TE. Profile of depressive symptoms in younger and older medical inpatients with major depression. J Am Geriatr Soc 1993; 41: 1169-76.

22 Stage $K B$, Bech $P$, Kragh-Sorensen $P$, Nair NP, Katona $C$. Differences in symptomatology and diagnostic profile in younger and elderly depressed inpatients. J Affect Disord 2001; 64: 239-48.

23 Wallace J, Pfohl B. Age-related differences in the symptomatic expression of major depression. J Nerv Ment Dis 1995; 183: 99-102.

24 Balsis S, Cully JA. Comparing depression diagnostic symptoms across younger and older adults. Aging Ment Health 2008; 12: 800-6.

25 Garvey MJ, Schaffer CB. Are some symptoms of depression age dependent? $J$ Affect Disord 1994; 32: 247-51.

26 Reischies FM, von Spiess P, Stieglitz RD. The symptom pattern variations of unipolar depression during life span: a cross-sectional study. Compr Psychiatry 1990; 31: 457-64.

27 Husain MM, Rush AJ, Sackeim HA, Wisniewski SR, McClintock SM, Craven N, et al. Age-related characteristics of depression: a preliminary STAR*D report. Am J Geriatr Psychiatry 2005; 13: 852-60.

28 Musetti L, Perugi G, Soriani A, Rossi VM, Cassano GB, Akiskal HS. Depression before and after age 65. A re-examination. Br J Psychiatry 1989; 155: 330-6.

29 Weissman MM. The myth of involutional melancholia. JAMA 1979; 242 742-4.

30 Wesner RB, Winokur G. An archival study of depression before and after age 55. J Geriatr Psychiatry Neurol 1988; 1: 220-5.

31 Blazer D, Bachar JR, Hughes DC. Major depression with melancholia: a comparison of middle-aged and elderly adults. J Am Geriatr SoC 1987; 35: 927-32

32 Corruble E, Gorwood P, Falissard B. Association between age of onset and symptom profiles of late-life depression. Acta Psychiatr Scand 2008; 118 389-94

33 Hyett MP, Parker GB, Proudfoot J, Fletcher K. Examining age effects on prototypic melancholic symptoms as a strategy for refining definition of melancholia. J Affect Disord 2008; 109: 193-7.

34 Marin RS. Differential diagnosis and classification of apathy. Am J Psychiatry 1990; 147: 22-30.

35 Newmann JP, Engel RJ, Jensen JE. Changes in depressive-symptom experiences among older women. Psychol Aging 1991; 6: 212-22.
36 Gatz M, Hurwicz ML. Are old people more depressed? Cross-sectional data on Center for Epidemiological Studies Depression Scale factors. Psychol Aging 1990; 5: 284-90.

37 Gurland BJ. The comparative frequency of depression in various adult age groups. J Gerontol 1976; 31: 283-92.

38 Bouwman WP. Sexual, ethics and medico-legal issues. In Oxford Textbook of Old Age Psychiatry (eds R Jacoby, C Oppenheimer, T Dening, A Thomas): 689-707. Oxford University Press, 2008.

39 Wetherell JL, Petkus AJ, McChesney K, Stein MB, Judd PH, Rockwell E, et al. Older adults are less accurate than younger adults at identifying symptoms of anxiety and depression. J Nerv Ment Dis 2009; 197: 623-6.

40 Naarding P, Schoevers RA, Janzing JG, Jonker C, Koudstaal PJ, Beekman AT. A study on symptom profiles of late-life depression: the influence of vascular, degenerative and inflammatory risk-indicators. J Affect Disord 2005; 88: 155-62.

41 Naarding P, Tiemeier H, Breteler MM, Schoevers RA, Jonker C, Koudstaal PJ, et al. Clinically defined vascular depression in the general population. Psychol Med 2007; 37: 383-92.

42 Newson RS, Hek K, Luijendijk HJ, Hofman A, Witteman JC, Tiemeier H. Atherosclerosis and incident depression in late life. Arch Gen Psychiatry 2010; 67: 1144-51.

43 Van der Mast RC, Vinkers DJ, Stek ML, Bek MC, Westendorp RG, Gussekloo J, et al. Vascular disease and apathy in old age. The Leiden 85-Plus Study. Int J Geriatr Psychiatry 2008; 23: 266-71.

44 Koenig HG, George LK, Peterson BL, Pieper CF. Depression in medically ill hospitalized older adults: prevalence, characteristics, and course of symptoms according to six diagnostic schemes. Am J Psychiatry 1997; 154: 1376-83.

45 De Coster L, Leentjens AF, Lodder J, Verhey FR. The sensitivity of somatic symptoms in post-stroke depression: a discriminant analytic approach. Int J Geriatr Psychiatry 2005; 20: 358-62.

46 Leentjens AF, Verhey FR, Lousberg R, Spitsbergen $\mathrm{H}$, Wilmink FW. The validity of the Hamilton and Montgomery-Asberg depression rating scales as screening and diagnostic tools for depression in Parkinson's disease. Int J Geriatr Psychiatry 2000; 15: 644-9.

47 Lyness JM, Pearson JL, Lebowitz BD, Kupfer DJ. Age at onset or late-life depression: a research agenda report of a MacArthur Foundation-NIMH workshop. Am J Geriatr Psychiatry 1994; 2: 4. 